BBA 76757

\title{
SOME FACTORS AFFECTING THE VALINOMYCIN-INDUCED LEAK FROM LIPOSOMES
}

\author{
M. C. BLOK, J. DE GIER and L. L. M. VAN DEENEN
}

Laboratory of Biochemistry, University of Utrecht, Transitorium 3, University Centre "De Uithof", Padualaan 8, Utrecht (The Netherlands)

(Received May 8th, 1974)

\section{SUMMARY}

Experiments dealing with the valinomycin-induced $\mathrm{K}^{+}$leak from egg lecithin liposomes have demonstrated the importance of the enclosed anion. Except when lipophilic anions are enclosed, the addition of both valinomycin and a uncoupler, e.g. carbonylcyanide $p$-trifluoromethoxyphenylhydrazone, is necessary to induce a significant increase of the $\mathrm{K}^{+}$leak. In the presence of uncouplers the leak of $\mathrm{K}^{+}$is accompanied by an inward transport of $\mathrm{H}^{+}$generating a $\mathrm{pH}$ gradient over the membrane. Within the liposomes a considerable acidification takes place, resulting in the formation of undissociated acid molecules which rapidly permeate the membrane and produce, as a net result, the translocation of a pottassium ion and an anion. This hypothesis was tested by measuring fluxes of $\mathrm{K}^{+}, \mathrm{H}^{+}$and the enclosed anion. Furthermore, it is shown that when valinomycin is preincubated in alcohol : water mixtures, the effect of the ionophore on the initial increase of the $\mathrm{K}^{+}$leak from liposomes containing potassium thiocyanate decreases at ratios less than $50: 50$. This phenomenon is primarily caused by a reversible inactivation of the ionophore, possibly due to a conformational change, which is followed by partial absorption to the wall of the reaction vessel.

\section{INTRODUCTION}

The ionophore valinomycin specifically increases the permeability of natural and artificial membranes for certain alkali ions: $\mathrm{Rb}^{+}>\mathrm{K}^{+} \geqq \mathrm{Cs}^{+}>\mathrm{Na}^{+}>\mathrm{Li}^{+}$ [1]. The effect of the ionophore on the cationic fluxes however, strongly depends on the system to which it is added.

When valinomycin is added to membrane systems, such as mitochondria [2-5] or bacterial membrane vesicles [6,7], an energy-linked accumulation of alkali ions can be demonstrated. Furthermore, the antibiotic drastically increases cationic exchange diffusion through non-energized membranes if complexable cations are present on both sides [8-10]. For reasons of electrogenic neutrality, however, the induced

Abbreviation: FCCP, carbonylcyanide p-trifluoromethoxyphenylhydrazone. 
fluxes normally are very limited if the complexable cation is present on only one side $[8,18-13]$.

In the latter case both valinomycin and an uncoupler are necessary to give a significant increase of the alkali ionic flux [8, 11-13]. Under these conditions the valinomycin-mediated alkali ionic flux is accompanied by an uncoupler-mediated transport of $\mathrm{H}^{+}$in the opposite direction, as reflected by changes in $\mathrm{pH}[8,12,14]$. The unidirectional transport of $\mathrm{H}^{+}$generates a $\mathrm{pH}$ gradient across the membrane that will inhibit subsequent transport of $\mathbf{H}^{+}$. It has been suggested that in the acidifying compartment undissociated acid molecules are formed. These neutral molecules would readily permeate through the membrane, giving as a net result the translocation of an alkali ion and an anion $[8,15]$. In the present study experiments were undertaken to test this hypothesis. In addition, it will be shown that the effect of valinomycin on the $\mathrm{K}^{+}$leak from liposomes strongly depends on the chemical nature of the anions enclosed in the liposomes.

During the course of the experiments it was found that preincubaton of the ionophore in the reaction medium results in a marked reduction of the valinomycininduced $\mathrm{K}^{+}$leak from liposomes, added subsequently. This phenomenon was further explored, and a possible explanation is discussed.

\section{MATERIALS AND METHODS}

Egg lecithin was purified from egg yolk by acetone precipitation and subsequent chromatography over alumina oxide and silica gel. Phosphatidic acid was prepared from egg lecithin by degradation with phospholipase D extracted from Savoy Cabbage [16]. Valinomycin was obtained from Calbiochem, Los Angeles, California, U.S.A.; lactate dehydrogenase and NADH were from Boehringer, Mannheim, Germany. Carbonylcyanide $p$-trifluoromethoxyphenylhydrazone (FCCP) was generously supplied by Dr P. G. Heyter, Du Pont Co., Wilmington, Delaware, U.S.A. All other reagents were commercial and of analytical reagent grade.

Multilayered liposomes were prepared in solutions of a potassium salt from mixtures of 98 mole $\%$ egg yolk lecithin and 2 mole $\%$ phosphatidic acid, as described previously [17]. The outside $\mathrm{K}^{+}$was removed by dialysis against ice-cold, isotonic $150 \mathrm{mM} \mathrm{MgSO}_{4}$ solutions.

Changes in $\mathrm{K}^{+}$and $\mathrm{H}^{+}$activities were monitored by a potassium-glass electrode (Philips, type G15K) and a pH electrode (Radiometer, type GK230IC), respectively, connected to an Ion Activity Meter (Philips, type PW9413) or a pH meter (Radiometer, type PHM26) and a recorder. The leak of pyruvate was measured enzymatically by conversion to lactate with lactate dehydrogenase (EC 1.1.1.27, present in excess; 2.5 units per $\mathrm{ml}$ ) and NADH. The decrease in the absorbance at $340 \mathrm{~nm}$ was followed continuously with a Hitachi-Perkin Elmer Double Beam Spectrophotometer Model 356 in dual mode, using $450 \mathrm{~nm}$ as reference wavelength.

Measurements were performed at $30{ }^{\circ} \mathrm{C}$ in $150 \mathrm{mM} \mathrm{MgSO}_{4}, 10 \mathrm{mM}$ Tris$\mathrm{H}_{2} \mathrm{SO}_{4}$ solutions ( $\mathrm{pH} 7.3$ ), except for $\mathrm{pH}$ measurements which were carried out in

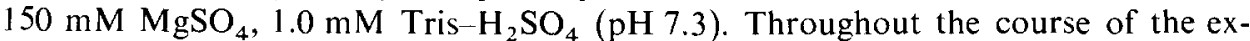
periment the solutions were stirred vigorously. For $\mathrm{K}^{+}$and $\mathrm{H}^{+}$measurements the final volume was $5.0 \mathrm{ml}$, and for pyruvate measurements $1.0 \mathrm{ml}$. Valinomycin and FCCP, dissolved in alcohol, were added in microliter amounts. 
Calibration of the electrodes was made in each experiment by adding, in a separate sample under identical experimental conditions, a series of fixed amounts of $\mathrm{K}^{+}$or $\mathrm{H}^{+}$.

\section{RESULTS AND DISCUSSION}

In order to measure the effect of the enclosed anion on the valinomycininduced $\mathrm{K}^{+}$leak from liposomes, these membranes were prepared in solutions of different $\mathrm{K}^{+}$salts. Only in the case of liposomes which contain KCNS (Fig. I) does the addition of valinomycin alone result in a strong increase of the leak. Although the amount of potassium trapped in the liposomes was different for the various liposome-preparations (Table I), the ion concentration gradient across the outer liposomal bilayer is initially the same. Therefore, the initial increase of the leak following the addition of the ionophore is expected to be independent of the amount of $\mathrm{K}^{+}$ trapped. It is clear that the initial increase in the potassium leak is greatest when the
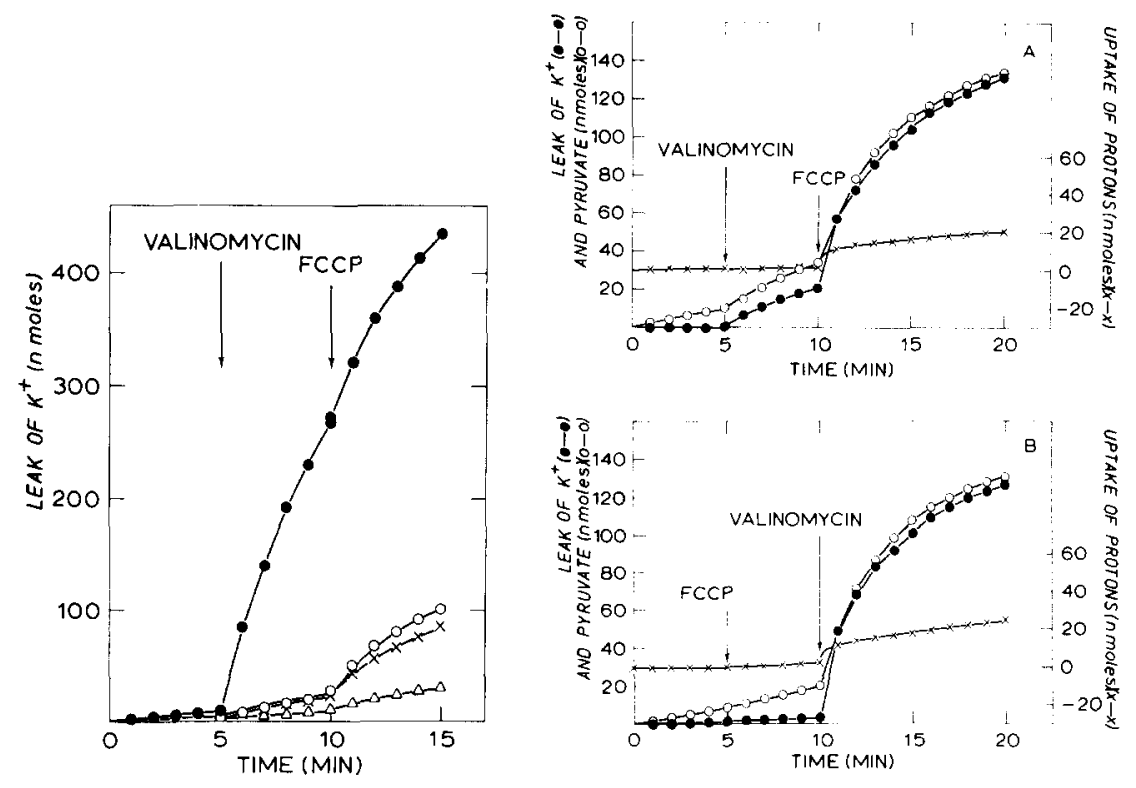

Fig. 1. The effect of the enclosed anion on the valinomycin plus FCCP-induced $\mathrm{K}^{+}$leak from egg lecithin liposomes. Liposomes were prepared in $150 \mathrm{mM} \mathrm{KCNS}(-0), 150 \mathrm{mM}$ potassium pyruvate $(\mathrm{O}-\mathrm{O}), 150 \mathrm{mM} \mathrm{KCL}(\times-x)$, and $100 \mathrm{mM} \mathrm{K}_{2} \mathrm{SO}_{4}(\Delta-\triangle)$, followed by dialysis against ice-cold $150 \mathrm{mM} \mathrm{MgSO} 4$ to remove the outside $\mathrm{K}^{+}$. The $\mathrm{K}^{+}$leak from the liposomes $(0.15 \mu$ mole liposomal phospholipid $\mathrm{ml}^{-1}$ ) was monitored as described in Materials and Methods, in $5.0 \mathrm{ml} 150 \mathrm{mM}$ $\mathrm{MgSO}_{4}, 10 \mathrm{mM}$ Tris $/ \mathrm{H}_{2} \mathrm{SO}_{4}, \mathrm{pH} 7.3$ at $30{ }^{\circ} \mathrm{C}$. Valinomycin and $\mathrm{FCCP}$ were added in microliter amounts at final concentration of $2.5 \cdot 10^{-3} \mu \mathrm{g} \cdot \mathrm{ml}^{-1}$ and $0.2 \mathrm{mg} \cdot \mathrm{ml}^{-1}$, respectively.

Fig. 2. Measurement of the $\mathrm{K}^{+}, \mathrm{H}^{+}$and pyruvate fluxes from egg lecithin liposomes containing potassium pyruvate in the presence of valinomycin and FCCP. The fluxes were measured as described in Materials and Methods from $0.15 \mu \mathrm{mole}$ of liposomal phospholipid $\cdot \mathrm{ml}^{-1}$. Final concentrations of valinomycin and FCCP were $5.0 \cdot 10^{-3} \mu \mathrm{g} \cdot \mathrm{ml}^{-1}$ and $0.02 \mu \mathrm{g} \cdot \mathrm{ml}^{-1}$. The fluxes of pyruvate which were measured in a final volume of $1.0 \mathrm{ml}$, are multiplied by a factor of 5 in order to compare them with $\mathrm{K}^{+}$and $\mathrm{H}^{+}$fluxes, which were measured in $5.0 \mathrm{ml}$. 
TABLE I

THE AMOUNT OF $\mathrm{K}^{+}$TRAPPED IN EGG LECITHIN LIPOSOMES PREPARED IN VARIOUS POTASSIUM SALTS

Liposomes were prepared as described in Fig. 1. The amount of $\mathrm{K}^{+}$trapped was determined by lysing the liposomes in the reaction mixture under normal experimental conditions by adding $0.1 \mathrm{ml}$ of a $10 \%$ Triton X-100 solution, followed by a correction for the electrode-effect of the Triton.

\begin{tabular}{|c|c|c|}
\hline \multicolumn{2}{|c|}{ Liposomes prepared in } & \multirow{2}{*}{$\begin{array}{l}\text { nmoles of } \mathrm{K}^{+} \text {trapped } \\
\text { per } \mu \text { mole of liposomes: }\end{array}$} \\
\hline Potassium salt & Concentration & \\
\hline KCNS & $150 \mathrm{mM}$ & 586 \\
\hline Potassium pyruvate & $150 \mathrm{mM}$ & 167 \\
\hline $\mathrm{KCl}$ & $150 \mathrm{mM}$ & 395 \\
\hline $\mathrm{K}_{2} \mathrm{SO}_{4}$ & $100 \mathrm{mM}$ & 184 \\
\hline
\end{tabular}

liposomes contain a lipophilic anion, such as thiocyanate. This finding is in agreement with the demonstration that liposomes show a valinomycin-induced swelling if suspended in media containing lipophilic anions [18]. The lipophilic thiocyanate anion seems not to affect the barrier properties of the lipid bilayer itself, for in contrast to salicylate, the exchange diffusion of ${ }^{22} \mathrm{Na}$ is not elevated in comparison to a number of non-lipophilic anions if these anions are present on both sides of the membrane [27]. The coupling of the anion transport with the cation transport in this special case will be discussed in the accompanying paper [19].

In all other cases tested, using enclosed impermeable anions, the addition of both valinomycin and an uncoupler was necessary to effect a significant increase in the $\mathrm{K}^{+}$leak. This is in agreement with previous studies [8, 11-13]. Fig. 1 furthermore, shows that the increase in the valinomycin plus FCCP-induced potassium leak from liposomes containing $\mathrm{K}_{2} \mathrm{SO}_{4}$ is much smaller than in the cases where pyruvate or chloride were the enclosed anions. This difference is most easily explained by supposing that the anion plays an important role in the induced cationic permeabilities, as discussed in the Introduction. In liposomes containing $\mathrm{K}_{2} \mathrm{SO}_{4}$ or $\mathrm{KCl}$ the formation of undissociated acid molecules will be less than in those containing potassium pyruvate. Furthermore, upon consideration of the size and polarity of the undissociated acid molecules, it is likely that diffusion of $\mathrm{H}_{2} \mathrm{SO}_{4}$ molecules through the membrane is much slower than that of $\mathrm{HCl}$ molecules. These two factors together result in the highest acidification in liposomes containing $\mathrm{K}_{2} \mathrm{SO}_{4}$ and, in turn, give the strongest inhibition of the cationic fluxes.

In order to examine the role of the anion in the valinomycin plus FCCP-induced $\mathrm{K}^{+}$leak from liposomes containing $\mathrm{K}^{+}$and an inpermeable anion, the fluxes of $\mathrm{K}^{+}$, $\mathrm{H}^{+}$and pyruvate through the bilayers of liposomes containing potassium pyruvate were measured under identical conditions as described in Materials and Methods. Fig. $2 \mathrm{a}$ shows that in the absence of ionophores there is a very limited leak of $\mathrm{K}^{+}$. The slight leak of pyruvate may be explained by an exchange diffusion of pyruvic acid against carbonic acid. The addition of valinomycin alone gives only a moderate increase in the $\mathrm{K}^{+}$leak, accompanied by a slight increase of the pyruvate leak. The increase in the pyruvate leak may be caused by an increase in the diffusion of the charged anion as a result of the membrane potential generated by the valinomycin- 
induced $\mathrm{K}^{+}$permeability. The amount of $\mathrm{K}^{+}$that should leak to generate a certain membrane potential can be calculated if the capacitance of the lipid bilayer and the outer surface of the liposomes are known. The capacitance of a phospholipid bilayer is in the order of $0.9 \mu \mathrm{F} / \mathrm{cm}^{2}$ [20] whereas the outer surface of our liposomes will be about $300 \mathrm{~cm}^{2} / \mu$ mole of lipid [21]. From these data it can be calculated that a net translocation of about three pmoles $\mathrm{K}^{+}$across the outer bilayer of one $\mu$ mole of liposomes would generate a membrane potential of $100 \mathrm{mV}$. This means that fluxes of $\mathrm{K}^{+}$well below our detection limit generate membrane potentials which could, indeed, alter the diffusion of the charged anions. The addition of FCCP (Fig. 2a) strongly enhanced the $\mathrm{K}^{+}$leak, produced a rapid alkalinisation of the medium, and led to a pronounced increase of the pyruvate leak. The quantitative movements of $\mathrm{H}^{+}$plus pyruvate together are, within experimental error, equivalent to the $\mathrm{K}^{+}$leak. That both valinomycin and FCCP together are necessary to induce this significant $\mathrm{K}^{+}$leak from the liposomes is shown in the reverse experiment (Fig. 2b). In the absence of valinomycin FCCP alone has no significant effect on the fluxes of cations and anions.

Although the alkalinisation of the medium in the presence of both valinomycin and uncoupler is restricted, the effect is very significant and suggests that the $\mathrm{pH}$ change inside the liposomes must be considerable. If we assume a value of $3 \mathrm{~mm}^{3}$ / $\mu$ mole of lipid [21] for the trapped volume of the liposomes, then the $\mathrm{pH}$ inside the liposomes decreased from about $\mathrm{pH} 7$ to about 2.3 during the first $30 \mathrm{~s}$ following the addition of the second ionophore. Moreover, a more pronounced alkalinisation of the medium was observed in experiments dealing with the valinomycin plus FCCP. induced $\mathrm{K}^{+}$leak from liposomes containing $\mathrm{KCl}$, indicating the lower $\mathrm{p} K$ of $\mathrm{HCl}$.

Fig. 1 showed that even in the absence of uncoupler the addition of valinomycin to liposomes containing KCNS resulted in a strong increase of the $\mathrm{K}^{+}$leak. The increase of the $\mathrm{K}^{+}$leak was maximal immediately following the addition of the antibiotic, suggesting the very rapid establishment of a partition equilibrium. In the accompanying paper [19] which describes the kinetics of the valinomycin-induced $\mathrm{K}^{+}$leak from these liposomes, it will be shown that the initial increase in the $\mathrm{K}^{+}$leak following the addition of valinomycin is directly proportional to the valinomycin concentration. In all the experiments discussed so far, the liposomes were present in the medium at the moment valinomycin was added. When however, as shown in Fig. 3, valinomycin was added to the medium prior to the addition of the liposomes, it appeared that the initial increase in the $\mathrm{K}^{+}$leak decreased with increasing time-intervals. This is in agreement with the finding of Lombardi et al. [7] that little or no energy-linked accumulation of $\mathrm{Rb}^{+}$takes place when valinomycin was added to the reaction mixtures prior to the addition of bacterial membrane vesicles. In an attempt to explain this phenomenon, the following experiment was done. A small volume of a concentrated valinomycin solution in alcohol was pipetted into alcohol-water mixtures of varying composition. After standing overnight we compared the $\%$ leak induced by these solutions relative to the leak induced by an equal sample of the solution in absolute alcohol. Fig. 4 a shows that the activity remains constant over the range alcohol: water $100: 0-50: 50$. At higher water concentrations the activity rapidly falls to a level of about $10 \%$ for the valinomycin solution in pure water. Restoring the $50: 50$ ratio by adding alcohol to the tube with the aqueous valinomycin solution and applying corrections for the volume changes showed complete recovery of the activity. This indicates that we are dealing with a reversible process and permits 


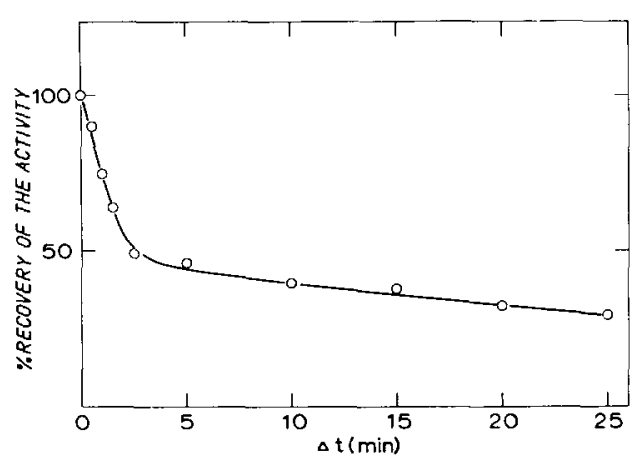

Fig. 3. Decrease of the initial increase of the $\mathrm{K}^{+}$leak from egg lecithin liposomes containing potassium thiocyanate with increasing time-intervals between the addition to the reaction mixture of valinomycin and liposomes added subsequently. For the preparation of the liposomes and measurement of the $\mathrm{K}^{+}$leak see Materials and Methods. The final concentration of valinomycin and of the liposomes were $4.0 \cdot 10^{-3} \mu \mathrm{g} \cdot \mathrm{ml}^{-1}$ and $0.20 \mathrm{mM}$, respectively.

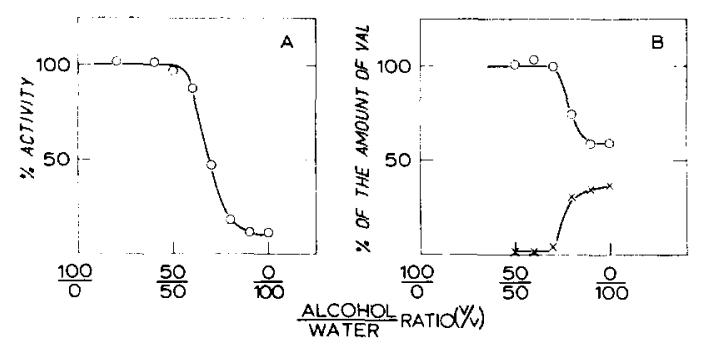

Fig. 4. The effect of the polarity of the solvent medium on the activity of valinomycin, determined by titration on egg lecithin liposomes containing potassium thiocyanate. (a) To $4.95 \mathrm{ml}$ of alcohol : water mixtures $50 \mu \mathrm{l}$ of a concentrated valinomycin solution in alcohol $\left(0.25 \mathrm{mg} \cdot \mathrm{ml}^{-1}\right)$ was added. After standing overnight at room temperature the initial increase of the $\mathrm{K}^{+}$leak from $\mathrm{KCNS}$-containing liposomes (final concentration $0.20 \mathrm{mM}$ ) was determined relative to the initial increase of the leak produced by the valinomycin solution in absolute alcohol. Liposomes and measurement of the $\mathrm{K}^{+}$ leak were as described in Materials and Methods. (b) From the solutions of valinomycin of Fig. 4a, $1.0 \mathrm{ml}$ was mixed with $1.0 \mathrm{ml}$ of suitable alcohol : water mixtures to give a final alcohol : water ratio of $50: 50$. After subsequently aspirating the solution, $5.0 \mathrm{ml}$ alcohol were added to the empty tube. The restored activity of valinomycin present in these solutions was determined by titration of $8 \mu \mathrm{l}$ of these solutions on KCNS-containing liposomes; $(\mathrm{O}-\mathrm{O})$, the quantity of valinomycin in solution, determined by measuring the activity after restoring the $50: 50$ alcohol : water ratio; $(\cdots, \cdot)$, the quantity of valinomycin adsorbed to the glass wall determined by measuring the activity of the alcohol added to the empty tube.

the discrimination between a conformational change of the dissolved ionophore and an adsorption to the glass wall to explain the origin of decreased activity at alcohol : water ratios less than $50: 50$.

The amount of valinomycin that remains in solution was determined by taking samples of the valinomycin-containing solutions and mixing them with equal volumes of suitable alcohol-water mixtures giving a final alcohol : water ratio of $50: 50$, followed by titration on liposomes. The quantity of valinomycin absorbed on the glass wall was measured by aspirating the solution and adding absolute alcohol to the 
empty tube, again followed by titration on lipsomes. The results of these manipulations are shown in Fig. 4b. At an alcohol : water ratio of $50: 50$ the activity has begun to decrease (Fig. 4a), whereas at a ratio of $30: 70$ all the valinomycin is still in solution (Fig. 4b). By further increasing the water concentration a partial adsorption of the ionophore at the glass wall takes place. Looking for an explanation of the observed decrease in the activity of the valinomycin, dissolved in alcohol : water mixtures smaller than $50: 50$, the finding that the conformation of valinomycin depends on the polarity of the medium is particularly relevant [22-24]. It has been shown that a stepwise opening of the molecule occurs with increasing polarity of the solvent medium [24]; such a conformational change may result in a decrease in the affinity of the antibiotic for the lipid bilayer and therefore in a decrease in the initial increase of the leak. The subsequent adsorption of valinomycin to the glass wall may be of some practical importance, especially with respect to selected black film studies. Stark and Benz [25], for example, have described experiments in which valinomycin was added to the aqueous phase prior to the formation of the black film. They stated that the conductivity increased over a rather long time period before a steady state was reached. A possible explanation may be that the ionophore, primarily adsorbed to the cell wall, must first desorb from this wall, a process which may be rather slow. It must be assumed, however, that under steady-state conditions the adsorption of valinomycin to the cell wall is negligible since the value of the partition constant of valinomycin between the aqueous phase and the membrane found in black film systems [26] shows a good similarity with those obtained from kinetic studies on the liposomal system, which will be presented in the accompanying paper [19].

\section{ACKNOWLEDGEMENTS}

The present investigations have been carried out under the auspices of the Netherlands Foundation for Biophysics and with financial aid from the Netherlands Organization for the Advancement of Pure Research (ZWO).

\section{REFERENCES}

I Eisenman, G., Szabo, G., McLaughlin, S. G. A. and Ciani, S. M. (1973) Bioenergetics, 4, 93-148

2 Moore, C. and Pressman, B. C. (1964) Biochem. Biophys. Res. Commun. 15, 562-567

3 Pressman, B. C. (1965) Proc. Natl. Acad. Sci. U.S. 53, 1076-1083

4 Azzi, A. and Azzone, G. F. (1966) Biochim. Biophys. Acta 113, 445-456

5 Ogata, E. and Rasmussen, H. (1966) Biochemistry 5, 57-66

6 Bhattacharyya, P., Epstein, W. and Silver, S. (1971) Proc. Natl. Acad. Sci. U.S. 68, $1488-1492$

7 Lombardi, F. J., Reeves, J. P. and Kaback, H. R. (1973) J. Biol. Chem. 248, 3551-3565

8 Henderson, P. J. F., McGivan, J. D. and Chapell, J. B. (1969) Biochem. J. 111, 521-535

9 Johnson, S. M. and Bangham, A. D. (1969) Biochim. Biophys. Acta 193, 82-91

10 de Gier, J., Haest, C. W. M., Mandersloot, J. G. and van Deenen, L. L. M. (1970) Biochim. Biophys. Acta 211, 373-375

11 Chapell, J. B. and Haarhoff, K. N. (1967) Biochemistry of Mitochondria (Slater, E. C., Kaniuga. Z. and Wojtczak, L., eds), pp 75-91, Academic Press, London

12 Harris, E. J. and Pressman, B. C. (1967) Nature 216, 918-920

13 Pressman, B. C., Harris, E. J., Jagger, W. S. and Johnson, J. H. (1967) Proc. Natl. Acad. Sci. U.S. $58,1949-1956$

14 Scarpa, A. and de Gier, J. (1971) Biochim. Biophys. Acta 241, 789-797 
15 de Gier, J., Demel, R. A., Haest, C. W. M., van Zutphen, H., van der Neut-Kok, E., Mandersloot, J. G., de Kruyff, B., Norman, A. W. and van Deenen, L. L. M. (1972) Molecular Mechanisms of Antibiotic Action on Protein Biosynthesis and Membranes (Munoz, E., Garcia-Fernandez, F. and Vazquez, D., eds), pp. 709-736, Elsevier, Amsterdam

16 Davidson, F. M. and Long, C. (1958) Biochem. J. 69, 458-466

17 de Gier, J., Mandersloot, J. G. and van Deenen, L. L. M. (1968) Biochim. Biophys. Acta 150. 666675

18 Singer, M. A. and Bangham, A. D. (1971) Biochim. Biophys. Acta 241, 687-692

19 Blok, M. C., de Gier, J. and van Deenen, L. L. M. (1974) Biochim. Biophys. Acta 367, 000-000

20 Montal, M. and Mueller, P. (1972) Proc. Natl. Acad. Sci. U.S. 69, 3561-3566

21 Bangham, A. D., de Gier, J. and Greville, G. D. (1967) Chem. Phys. Lipids 1, 225-246

22 Shemyakin, M. M., Ovchinnikov, Yu. A., Ivanov, V. T., Antonov, V. K., Vinogradova, E. I.. Shkrob, A. M., Malenkov, G. G., Evstratov, A. V., Laine, I. A., Melnik. E. I. and Ryabova, I. D. (1969) J. Mol. Biol. 1, 402-430

23 Patel, D. J. and Tonelli, A. E. (1973) Biochemistry, 12, 486-496

24 Grell, E. and Funck, T. (1973) Eur. J. Biochem. 34, 415-424

25 Stark, G. and Benz, R. (1971) J. Memb. Biol. 5, 133-153

26 Laüger, P. (1972) Science, 178, 24-30

27 Singer, M. A. (1973) Can. J. Physiol. Pharmacol. 51, 779-784 